\title{
MOLECULAR CHARACTERIZATION OF SOME BARLEY GENOTYPES Hordeum vulgare
}

(Received:5.2.2012)

\author{
By \\ K. Hassoun , M . Shaherly and S . Lawand \\ Department of Agronomy, Faculty of Agriculture, Damascus University, Syria
}

\begin{abstract}
The present research was conducted in biotechnology laboratory at the faculty of AgricultureDamascus University during the year 2010-2011. Six barley genotypes were grown in addition to two varieties white Arabi and black Arabi which have been utilized as a control in the research. To study the genetic diversity and to determine the degree of genetic relationship among these genotypes using inter simple sequence repeats (ISSR) technique have been used. The used primers proved its efficiency in showing polymorphism among the studied genotypes and the local varieties which resulted in a seventy one alleles. The percentage of this polymorphism reached $86.40 \%$. The number of bands for each primer accounted to a minimum of two bands for the primer (ISSR-34) and a maximum of seven bands with the primers (ISSR, 9-4-43) with an average of five bands for each primer. Both cluster analysis and dendogram showed that the highest degree of genetic relationship was between white Arabi and black Arabi varieties with a genetic distance of (8.41), followed by the two genotypes Acsad 1632 and Acsad 1670 with a genetic distance of (10.11). These results indicated the genetic diversity of the studied genotypes.
\end{abstract}

Key words: barley, cluster analysis, genetic diversity, molecular characterization, polymorphic, dendogram.

$$
\begin{aligned}
& \text { التوصيف الجزيئي لطرز وراثية من الثعير (Hordeum vulgare ) } \\
& \text { كنانه حسون - مخلص شاهرلي - سلام لاوند } \\
& \text { قسم المحاصيل الحقلية ـ كلية الزر اعة ـ جامعة دمشق - سوريا }
\end{aligned}
$$

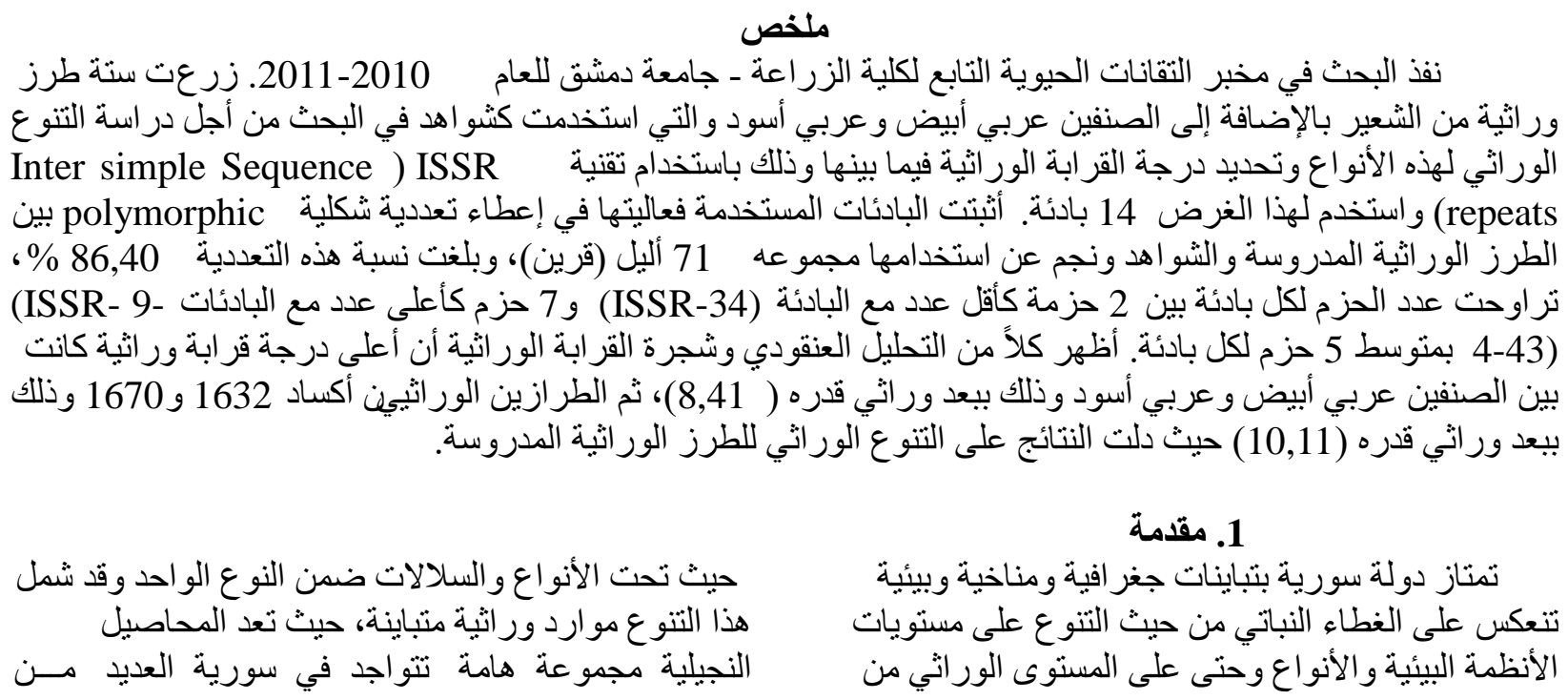

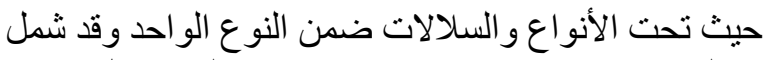

هذا التتوع موارد ور اثية متباينة، حيث تعد المحاصيل النيل

النجيلية مجموعة هامة تتواجد في سورية العديد مــن فينة 
5- الحصول على عدد كبير من المؤشرات بزمن قصير

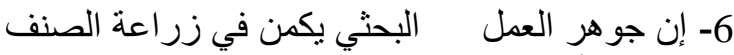

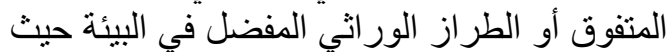

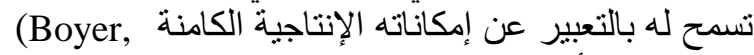

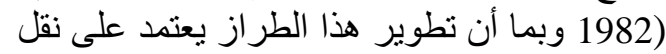

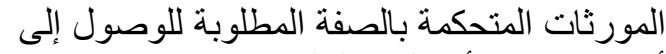

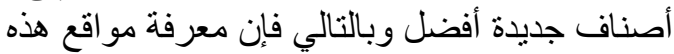

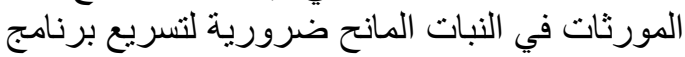

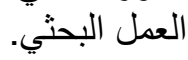

وقد ذكر (Powell et al., 1996) أن استخدام التقانات

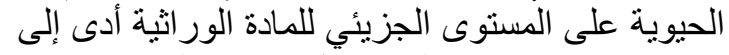

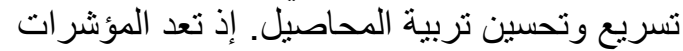

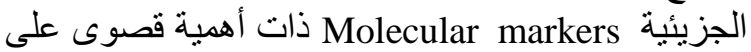
صعيد تربية النبات إضافة إلى أنها تعد مؤشرات اتشية مساعدة

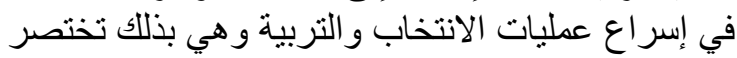

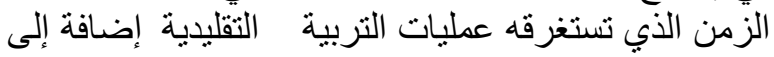
خفضها للتكاليف المادية (سيد، 2001) كما أوضح كل من ( Graner et al., 1991; Qi and (Lindhout, 1996; Ramsay et al., 2000 تقانات المؤشرات الجزيئية يمكن أن بقلل من تعقيدات إدخال

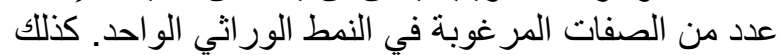

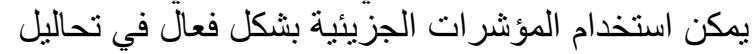
Powell et al., التنوع الور اثي وتقدير التثابه الوراثي

وقد طُور التفاعل التسلسلي البوليميرزي (البيسرة) 1996 من قبل الباحث (Polymerase Chain Reaction- PCR) (Saiki et al.,1985)

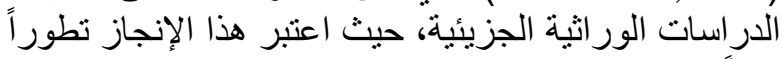

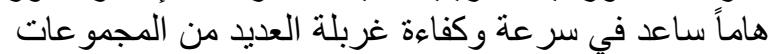

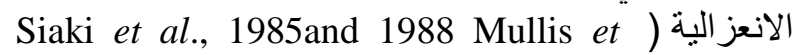
أل 1992

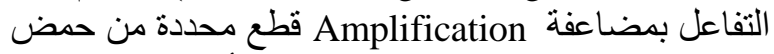

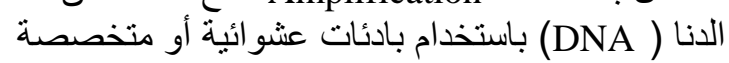

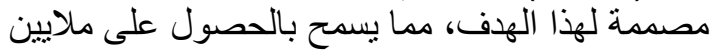

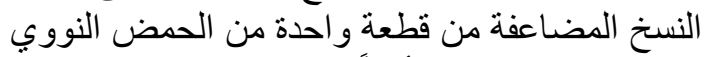

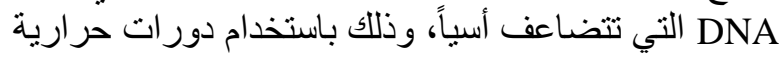
متعددة(Karp et al., 1997; Ayad et al., 1997 و سيد التياعل

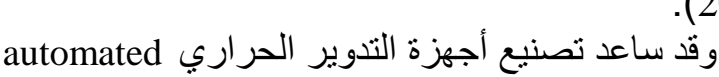

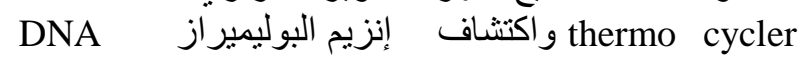

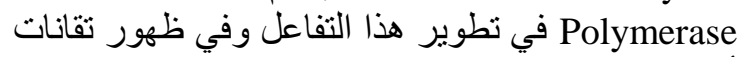
أخرى تعتمد عليه وتستخدم في إجر اء التحاليل الور اثنية

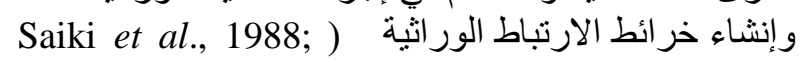
.Rafalski et al.,1996

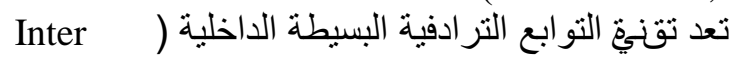

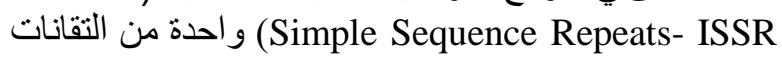
الهامة المعتمدة على تفاعل البيسرة Polymerase Chain)
أجناسها الغذائية و العلفية مما يجعلها من أهم مر اكز نشوء هذه الأجناس في هذه المنائ والعنطة

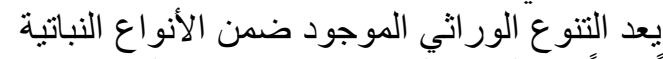

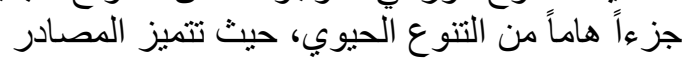

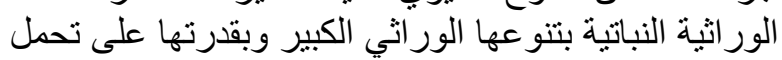

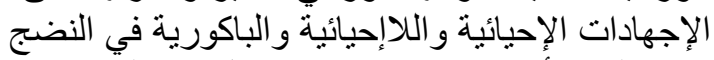

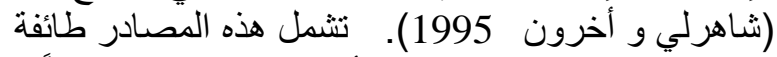

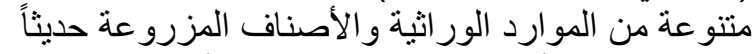

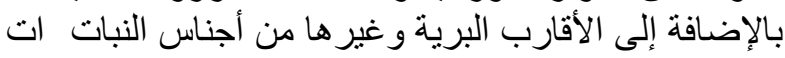

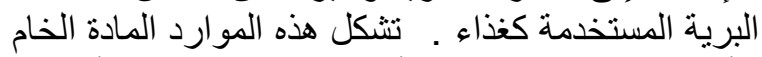

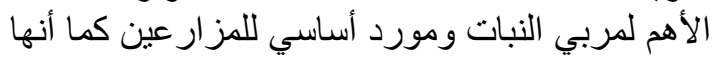
ذخيرة للنطويع الور اثي للوقاية من التخير ات التئي البيئية

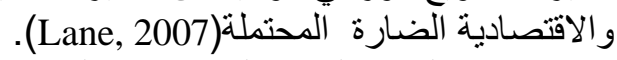

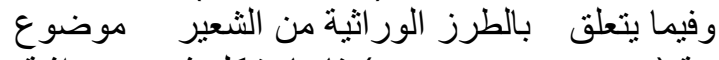

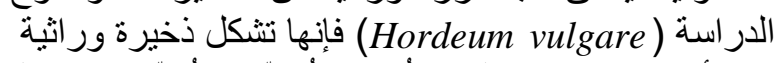

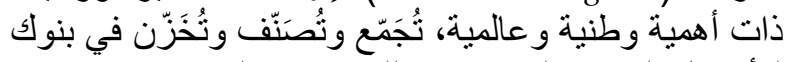

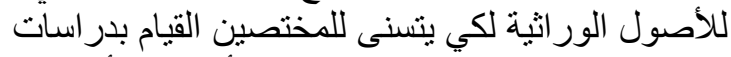

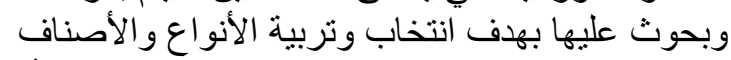

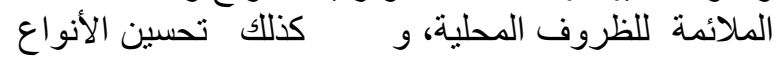

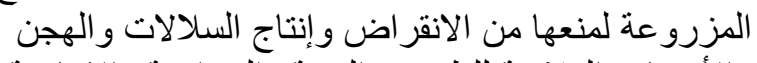

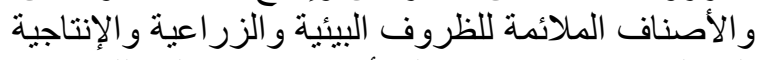

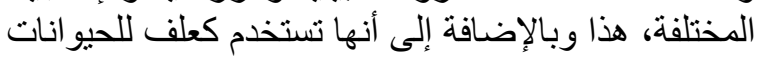

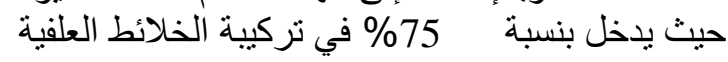

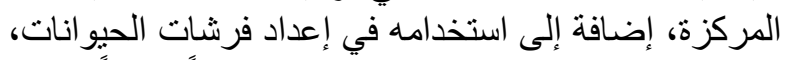

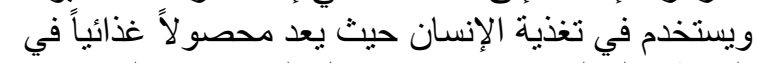

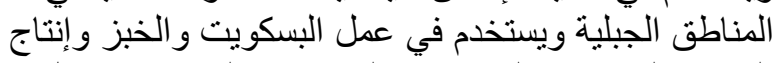

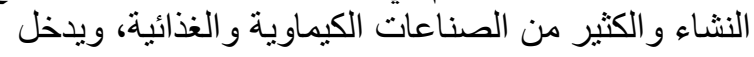

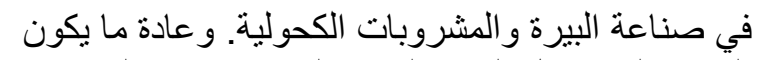

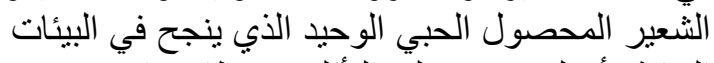

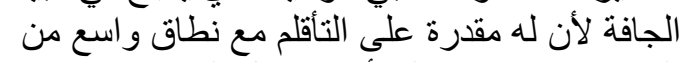

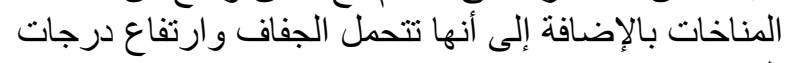

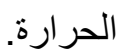

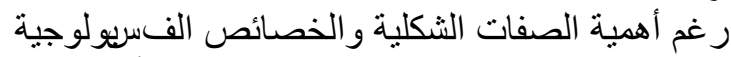

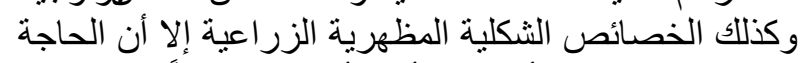

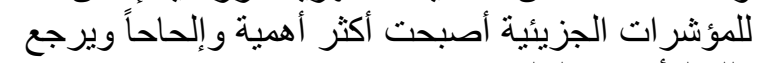
ذللك للأسباب التالية:

1- توفر المؤشر ات الجزيئية نتائج مبكرة مما يساعد في

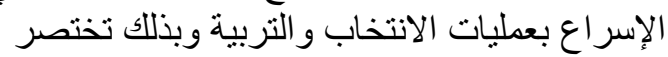

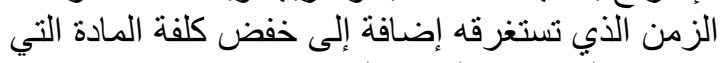

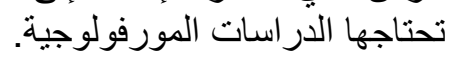

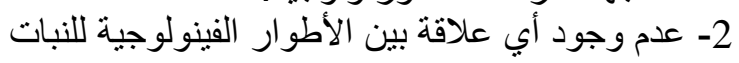

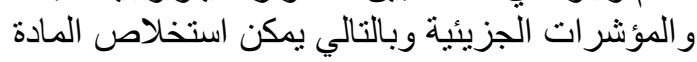

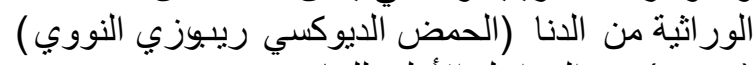
(DNA)

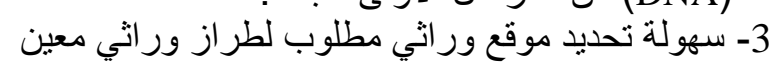

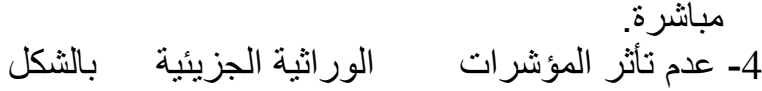
الظاهري للنباتات و المؤشرات الثرات البيئية كما في بر امج التربية التقليدية. 
كلوروفورم/أيزو اميل/ كحول بنسبة 1:24 ثم مزج الخليط لمدة 15 دقيقة باستخدام هزاز آلي في درجة حرارة برة

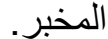
4- نقل المزيج إلى أنبوب تثفيل سعة 30 مل وثقل المزيج

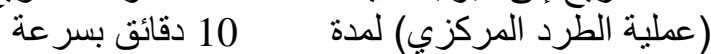
(10000 rpm)

5- تم أخذ الطبقة العليا (المتشكلة عن عملية التثقيل، و التي التي

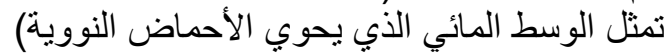
6وساطة ماصة ونقلت إلى أنابيب تثفيل جديدة.

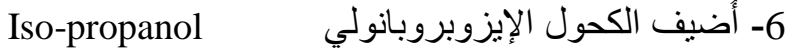
بمعدل 3/2 من حجم الوسط المائي ومز ج بهدوء بقلب

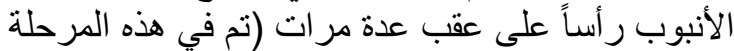
ترسيب الأحماض النووية على شكل كتلة خيطية هلامية التية

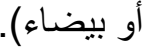

7- نقل الحمض النووي DNA المترسب بوساطة ماصة

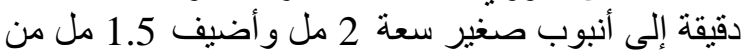

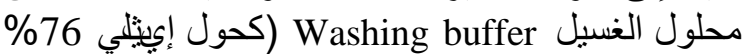
البارد المحفوظ بدرجة -20 مُم) وتركه لمدة 20 دقيقة في

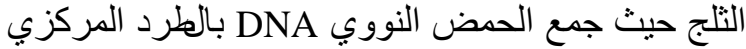

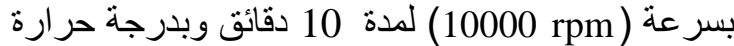
. 4

8- استبعد سائل الغسيل وحفظ الحمض النووي المتجمع في

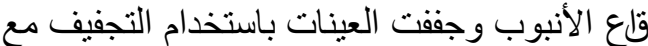
التفريغ الحر اري في مجفدة vacuum dryer لمدة التبن 1020

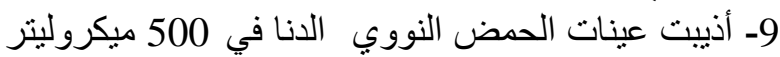

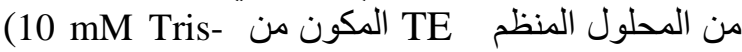
و عند درجة حرارة" HCl, 1mM EDTA)

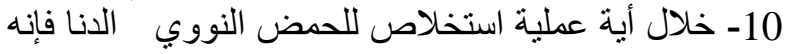

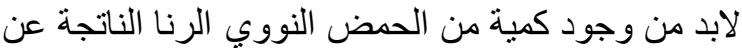

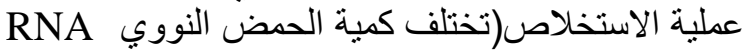

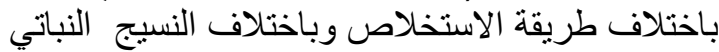
و عمره) و عليه فإنه لابد من استبعاد هذه الحمض النواني RNA وفق مايلي: وعلئ لإن

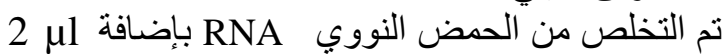

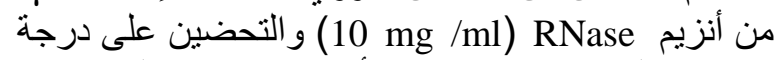

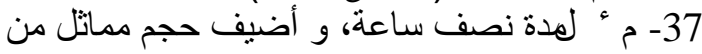

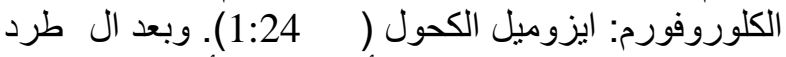
المركزي ونقل الطور العلوي لأنبوب جديد أضيف له له

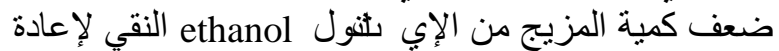

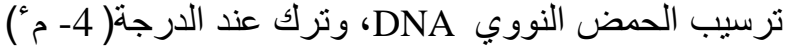

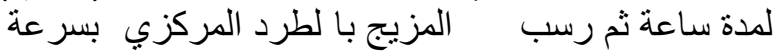

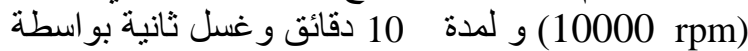

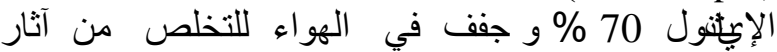

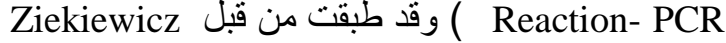
(et al.1994) و تعتبر مؤشر ات جزيئية مثالية للأسباب

تضخم منطقة التو ابع التر ادفية البسيطة ويستخدم بادئ وحيد

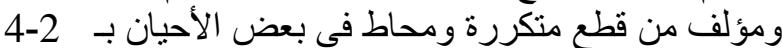

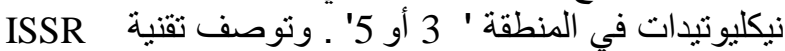

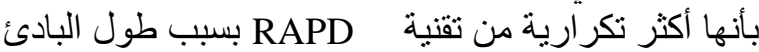

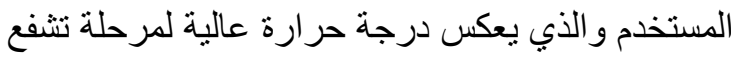

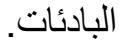

إمكانية الكثف عن التتاليات النيكليوتيدية ذات السيادة في (Borent and Branchard, 2001., التوريث. وفرتها وتو اجدها في مجينات Chowdhury et al., 2002) حقبقيات النوى النباتية و لا تحتاج إلى معلومات عن التسلسل فيل نتائجهاً ثابتة عند تكر ارها ها و وسريعة كما أنها تتطلب كمية

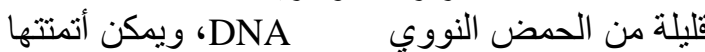
automation بسهولة بين المخابر بمجرد معرفة التسلسل النيكليوتيدي لهانيا. polymorphism تكثنف نسب عالية من التعددية النكلية

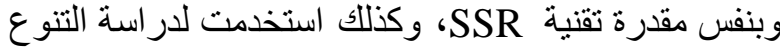
الور اثي في البطاطا (Bornet et al, 2002) ، الثعبر (Joshi et al والأرز (Fernandez et al., 2002)

(2000 و القمح (Nagaoka and Ogihara., 1997).

$$
\begin{aligned}
& \text { 2. المواد وطرق العمل } \\
& \text { 2. 1. المواد المستخدمة } \\
& \text { 2. 1. 1. المادة النباتية }
\end{aligned}
$$

تم الحصول على الطرز الور اثية المدروسة من المركز

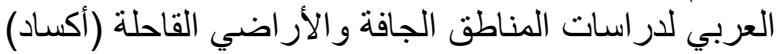

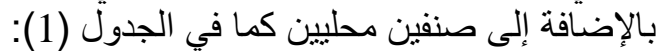

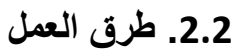

2. 2. 1 ـ استخلاص الحمض النول النووي بطريقة SDS: تم استخلاص الدنا وفق الخطو ات التخف التالية:

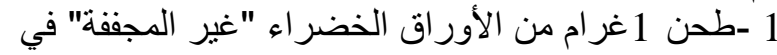

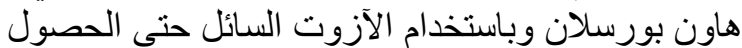

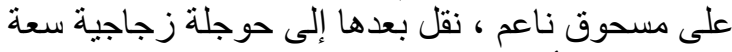

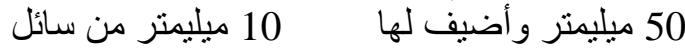

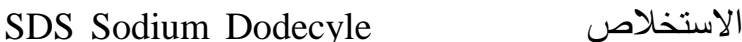
Tris 0.1M, pH=8.2, EDTA $50 \mathrm{mM}$, ) Sulphat ث مزجت جيداً. 2- تحضين العينات لمدة 60 دقيقة مع التحريك المستمر

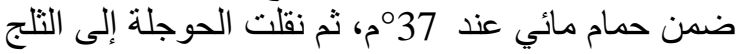
ووضعت فيه لمدة 5-10 دقائق. 2 - أضيف بعد ذللك 10 مليمترات من مزيج كل م-ن 
جدول رقم (1): الطرز الوراثية والأصناف المحلية المدروسة حيث اعتمد رمز محدد لكل سلالة.

\begin{tabular}{|c|c|c|}
\hline المواصفات & الرمز & الصنف \\
\hline معتمد في سورية، سداسي الصفوف، لون السنبلة والحبوب أبيض. & 1 & الصنف أكساد 176 \\
\hline ثنائية الصف، لون السنبلة أبيض، لون الحبوب أبيض. & 2 & السلالة أكساد 1420 \\
\hline ثنائية الصف، لون السنبلة أبيض، لون الحبوب أبيض. & 3 & السلالة أكساد 1614 \\
\hline سداسية الصفوف، لون السنبلة أبيض، لون الحبوب أبيض. & 4 & السلالة أكساد 1630 \\
\hline سداسية الصفوف، لون السنبلة أبيض، لون الحبوب أبيض. & 5 & السلالة أكساد 1632 \\
\hline سداسية الصفوف. & 6 & السلالة أكساد 1670 \\
\hline محلي قديم، ثنائي الصف، من أكثر الأصناف انتشارا في القطر & 7 & الصنف عربي أبيض \\
\hline صنف محلي قديم، ثنائي الصف، يأتي في المركز الثاني. & 8 & الصنف عربي أسود \\
\hline
\end{tabular}

(Williams et al., وفقاً لـ PCR أجري تفاعل البيسرة

(1990 مع اضافة بعض التعديلات فكان حجم التفاعل

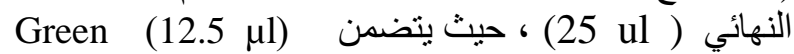
(Fermentas) (10 $\mu \mathrm{M}$ ) وبادئة بتركيز (25aster mix

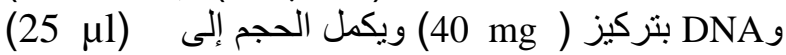
بالماء المقطر المعقم ، ويتم هذا التفاعل في جهاز التدوير التريل

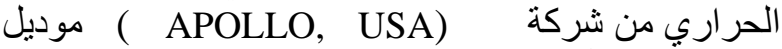
ATC401 وفقاً للظروف التالية :

جدول رقم ( 2) : التسلسل النكليوتيدي للبادئات الدختبرة في

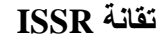

\begin{tabular}{|c|c|c|}
\hline الالتحام & التسلسل النكليوتيدي & البادئة \\
\hline 52 & (GA)8C & ISSR-2 \\
\hline 50 & (CA)8A & ISSR-3 \\
\hline 52 & (CA)8C & ISSR-4 \\
\hline 50 & (AC)8T & ISSR-5 \\
\hline 56 & $(\mathrm{GA}) 8 \mathrm{CG}$ & ISSR-6 \\
\hline 56 & (AC)8GG & ISSR-9 \\
\hline 56 & CCAG(GT)7 & ISSR-14 \\
\hline 56 & $\mathrm{C}(\mathrm{CT}) 4(\mathrm{GT}) 4 \mathrm{G}$ & ISSR-18 \\
\hline 52 & (GT)8G & ISSR-32 \\
\hline 50 & (GT)8 A & ISSR-33 \\
\hline 50 & (CT)8G & ISSR-34 \\
\hline 56 & (CA)8CC & ISSR-36 \\
\hline 50 & (AC)8TT & ISSR-40 \\
\hline 54 & (AG)9 & ISSR-43 \\
\hline
\end{tabular}

1- الانفصال : عند درجة حرارة 94 ْم لمدة 5 دقائق ليتم

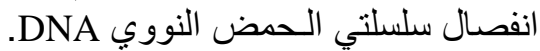

2- 35 دورة تتضمن كل منها المر احل التالية : التحطم : ينم عند حر ارة 94 مُ لم لمدة 30 ثنانية .

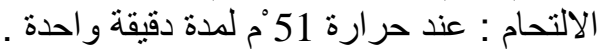
الاستطالة : عند حرارة 72 مْ لمدة دقيقة . 3- اكتمال التفاعل عند حر ارة 72 72 مُ مدة عشر دقة دقائق .

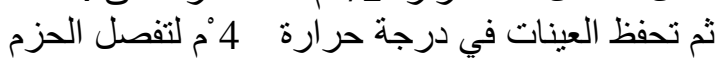
بعدها بالترحيل على هلامة الآغاروز. 2. 2 . 4 .التفريد الكهربائي والتلوين والتصوير التهائ
الإبيثنول ضمن جهاز المجفف بالتفريخ و الحرارة dry block Heater النووي DNA في محلول TE المعق.

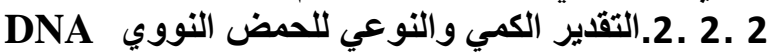

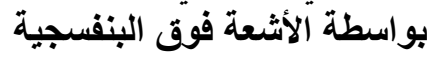

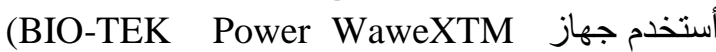

DNA لتقدير كمية الحمض النووي Instruments, Inc.)

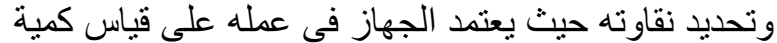

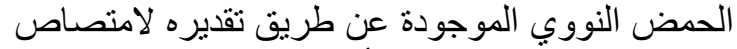

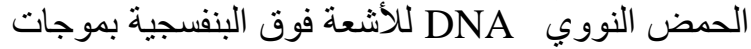

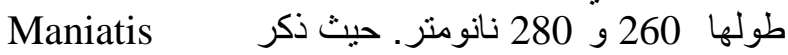
وأخرون عام 1982 أن النسبة بين قراءة المونة 280

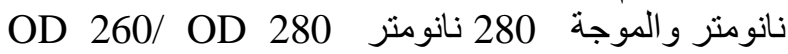

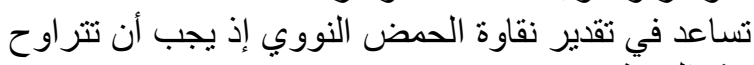

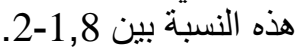

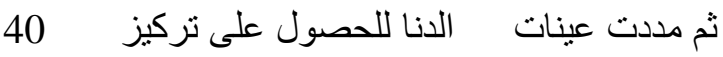
نانو غرام /ميكرولتر كما تم التقدير النوعي على هلى هلامة Agarose

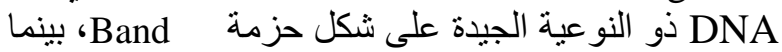

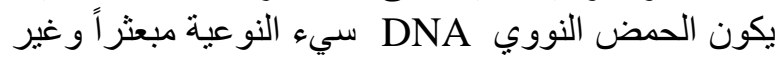
و اضح الحدود Smear. S. 2.2 3. 3. تقنية الـ $\quad$ ISSR المطبقة لإجراء الدراسة الجزيئية

Inter ) ISSR تضمنت هذه الدراسة تطبيق تقنية

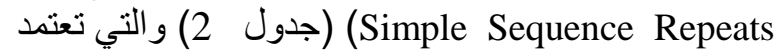
بشكل أساسي على تفاعل البلمرة المتسلسل (PCR) Polymerase Chain Reaction

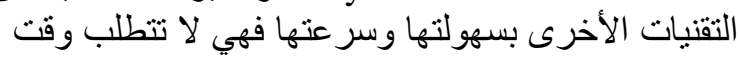
طويل(Williams et al., 1990) بالإضافة إلى ما تملكه هذه التقنية من وثوقية وتخصصية البناه عالية كونها تحتاج

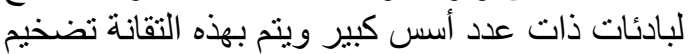
الحمض النووي DNA حيث يتم خلال تفاعل البلمرة إكثار قطعة من الحمض النوري النووي DNA و الحصول هلئ على على عدد كبير

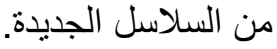


تضمنت الدر اسة (جدول 3) اختبار ستة طرز ور اثية

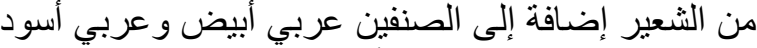

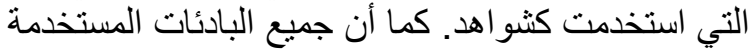

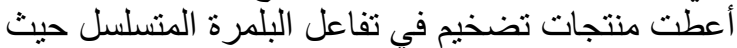

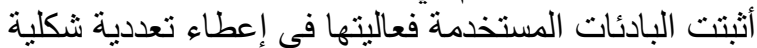

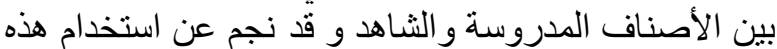

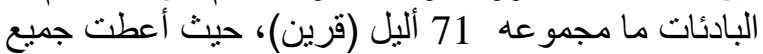

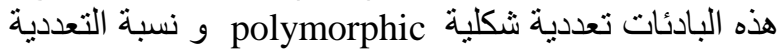

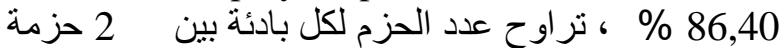

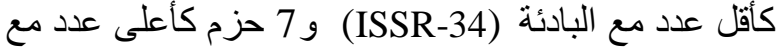

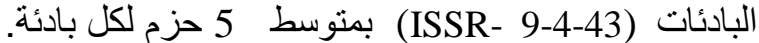
وكانت النسبة المئوية للتعددية الثكلية قد تراوحت بين $\% 100$ g 66,6

جدول ( 3): رموز البادئات المستخذمة، عدد الحزم الكلية

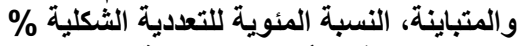
وحجم الحزم في الأنواع المدروسة.

\begin{tabular}{|c|c|c|c|}
\hline 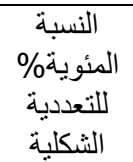 & ذات التعددية & عدد الحزم & \\
\hline 100 & 7 & 7 & ISSR-9 \\
\hline 75 & 3 & 4 & ISSR-32 \\
\hline 100 & 4 & 4 & ISSR-33 \\
\hline 50 & 1 & 2 & ISSR-34 \\
\hline 71.42 & 5 & 7 & ISSR-4 \\
\hline 83.33 & 5 & 6 & ISSR-2 \\
\hline 100 & 6 & 6 & ISSR-3 \\
\hline 80 & 4 & 5 & ISSR-5 \\
\hline 100 & 6 & 6 & ISSR-6 \\
\hline 66.66 & 2 & 3 & ISSR-14 \\
\hline 100 & 4 & 4 & ISSR-18 \\
\hline 100 & 4 & 4 & ISSR-36 \\
\hline 83.33 & 5 & 6 & ISSR-41 \\
\hline 100 & 7 & 7 & ISSR-43 \\
\hline 86.40 & 63 & 71 & المجموع \\
\hline
\end{tabular}

3.3. تحديد درجة القرابة الوراثية بين الأنواع المدروسة:

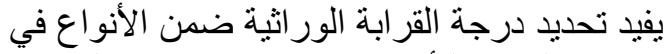

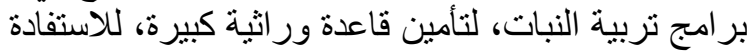

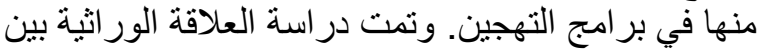

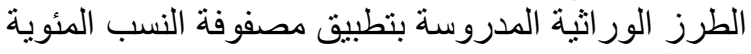

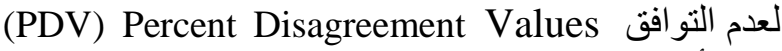

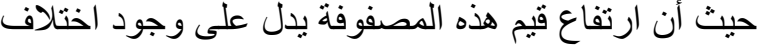
ور اثي وبازديادها يزداد التباين الور اثني بين النباتين

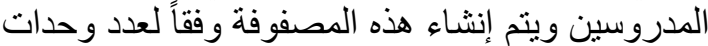
التضاعف المشتركة.

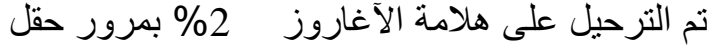

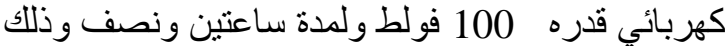

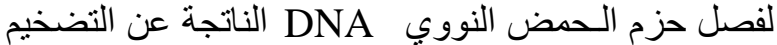

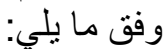

ـ تم إضافة و 2 من الآغاروز لـ 100 ml من المحلول buffer TBE 1X المنظم الافرو

(200 ml 5X TBE ،( EDTA buffer-Tris-acetate) buffer $+1800 \mathrm{ml}$ distilled water)

5X TBE buffer $(54 \mathrm{~g}$ Tris borate $+27.2 \mathrm{~g}$ Boric acid + $20 \mathrm{ml}$ 0.5 EDTA,pH 8.0)

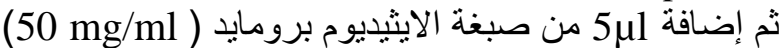
كما يتم حقن عينة من مؤشر الحمض النئن النوري

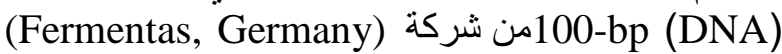
وذللك لتحديد الحجم الجزيئي للحزم الناتجة ليتم بعد ذلك

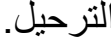

: Statistical analysis التحليل الإحصائي 2 .3. 2

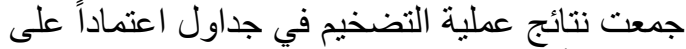

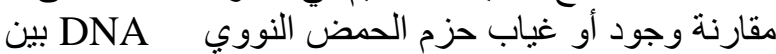
الطرز الور اثية المدروسة، حيث أعطي الرقم (

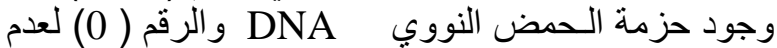

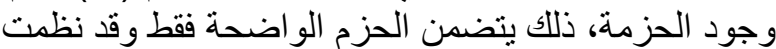

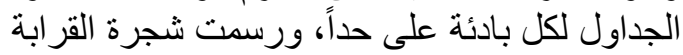

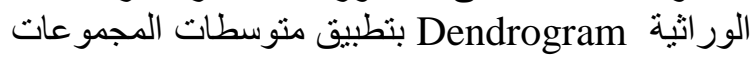
UPGMA Unweighted Pair الزوجية غير المرات النية Group Method with Arithmetic Averaging باستخدام برنامج Pop gene 1.31 الإحصائي.

\section{3.النتائج والمناقشة:}

3. 1. ا لاراسة الوراثية على مستوى الحمض النووي DNA

تم استخلاص الحمض النووي DNA من البادرات

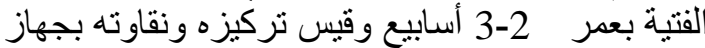

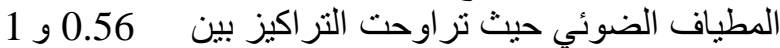

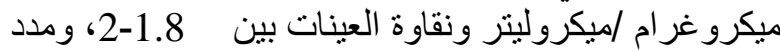

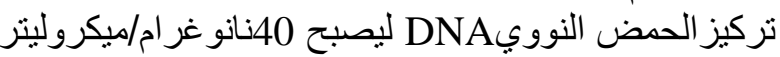

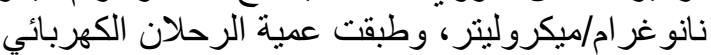

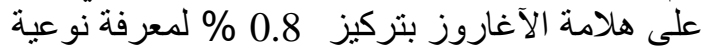
الحمض النووي DNA المستخدم (شكل 1) ثم طبقت تقنية ISSR فتم اختبار 14 بادئات. فأعطت هذه البادئات حزم و اضحة وذات تعددية شكلية كما يبين

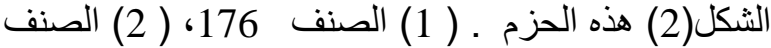

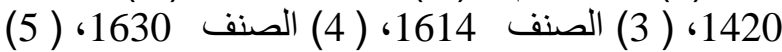
الصنف 1632 (6) الصنف (6) 1670، (7) (7) الصنف عربي أبيض، (8) الصنف عربي أسود.

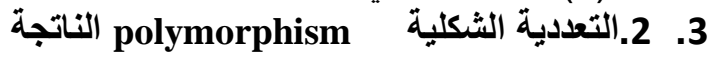
ISSR تطبيق تقنية الثكالة 


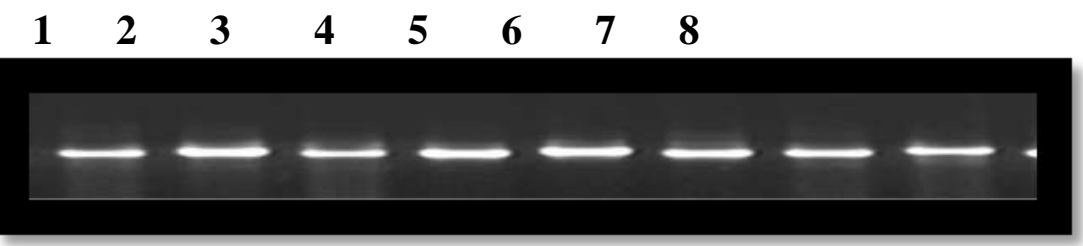

D.N.A.الثكل(1):هلامة الآغاروز بتركيز 0.8\% لتحديد نوعية الحمض النووى

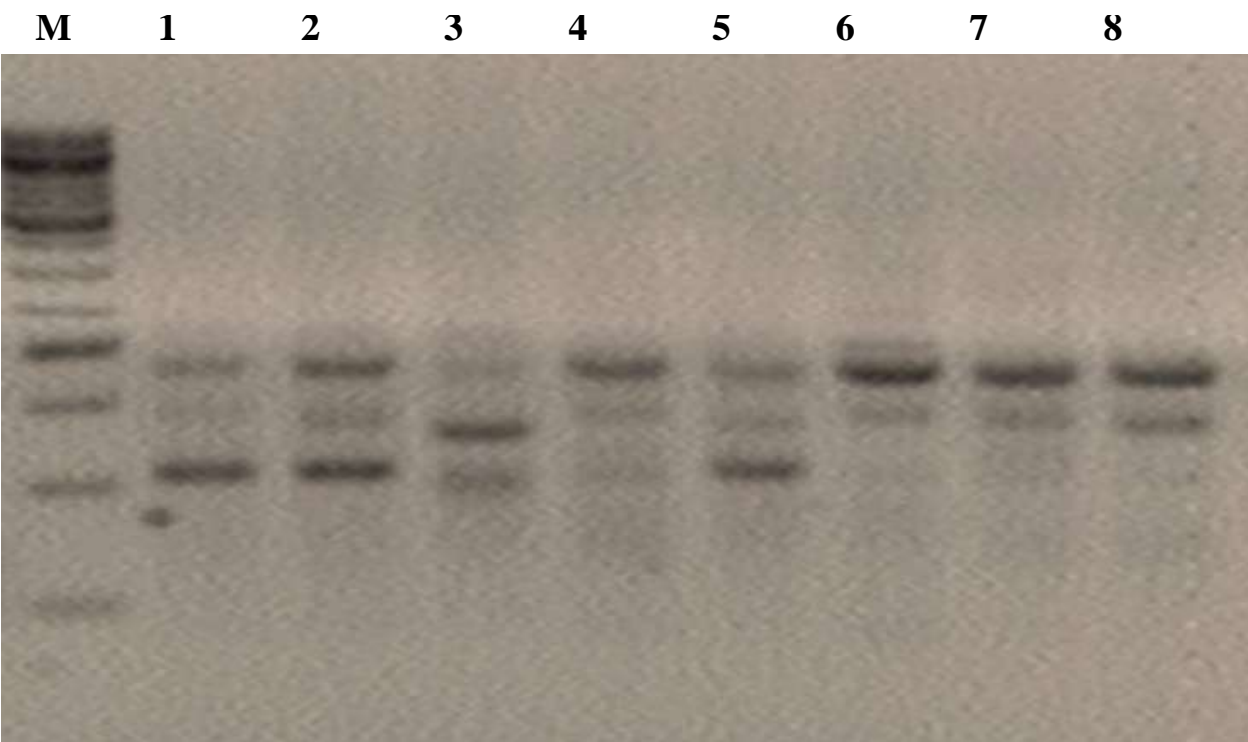

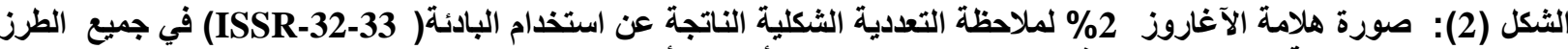

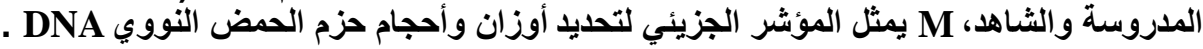

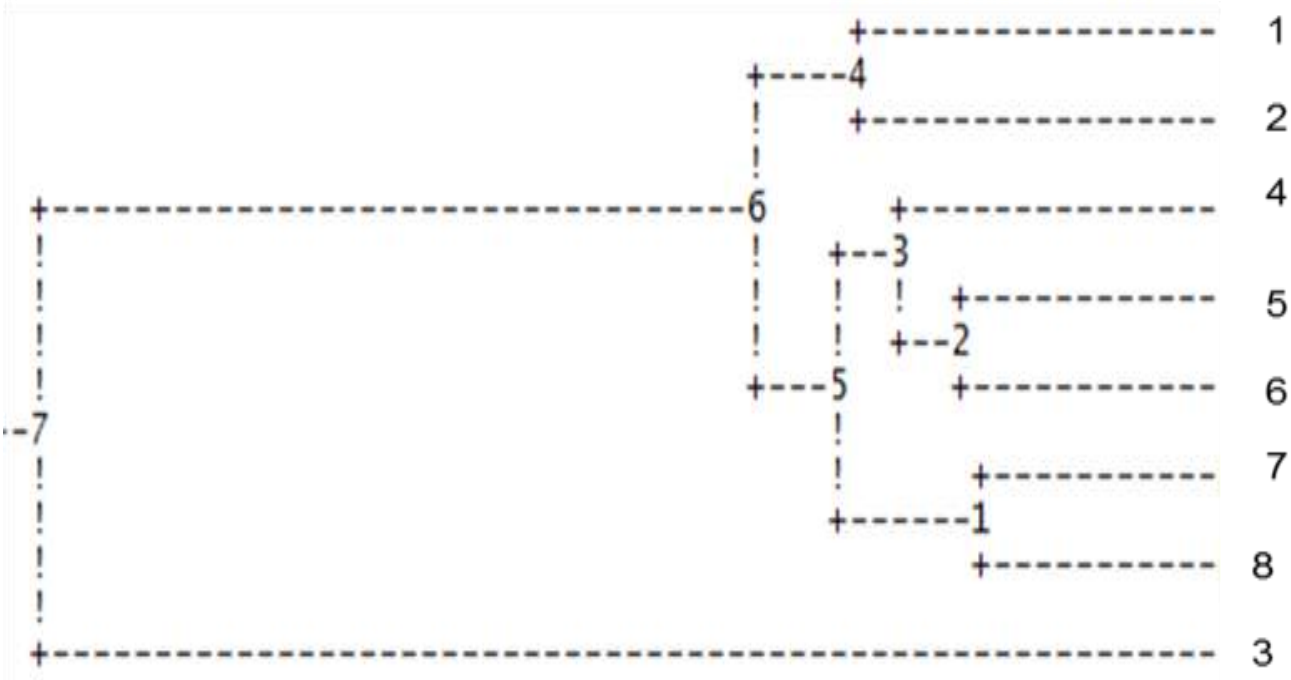

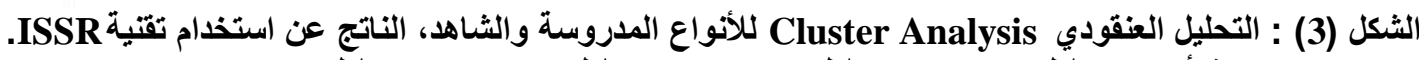

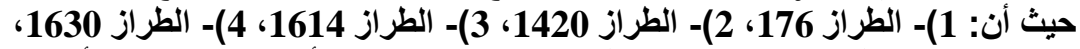
5)- الطراز 1632، 16) 16)- الطراز 1670، 7)- عربي أبيض، 8)- عربي أسود. 163. 


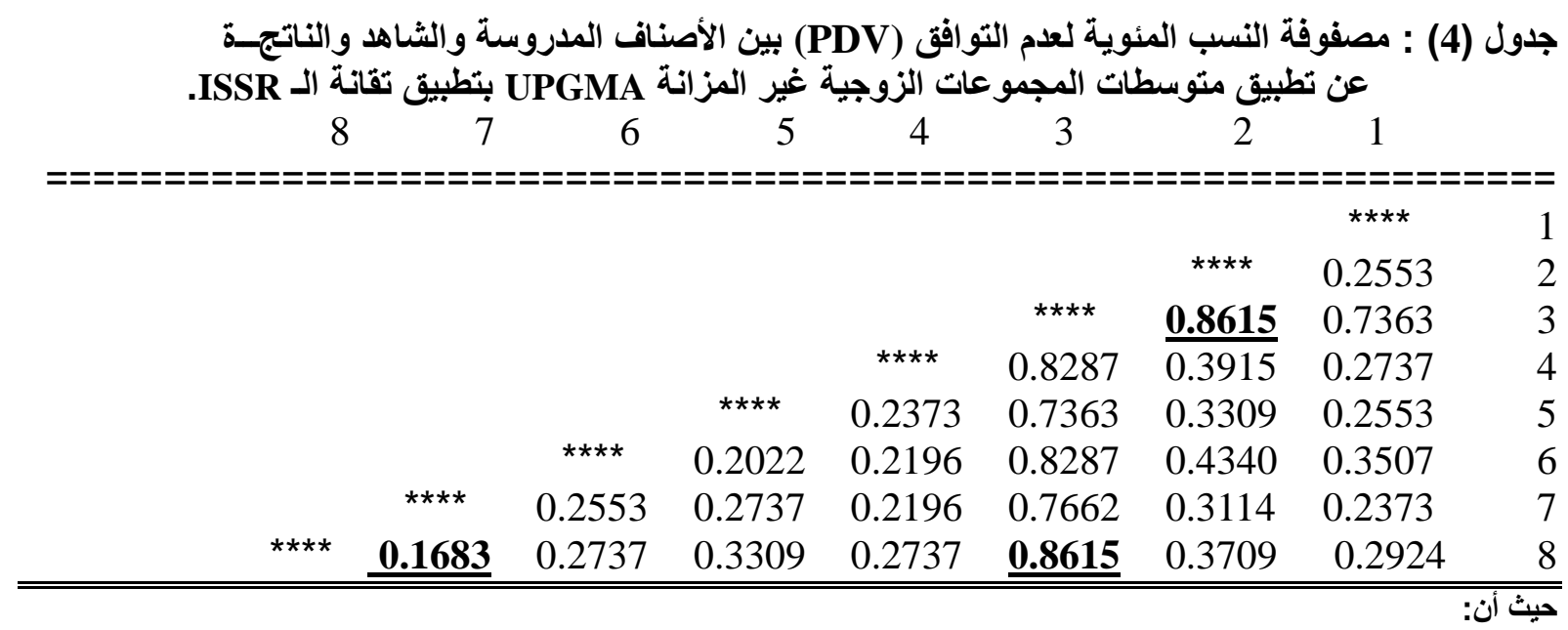

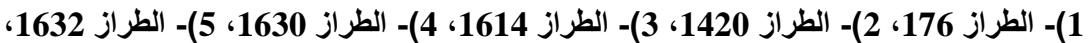

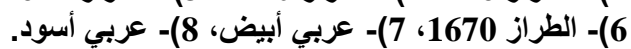

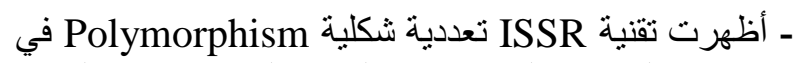
إظهار التباينات الوراثية بين الطرز الورية تاثية الثية حيث بلغت

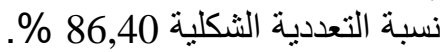
- انفصل الطر از الوراثي 1614 عن بقية الطرز و الأصناف في شجرة القر ابة الور اثية.

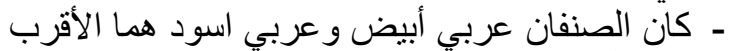

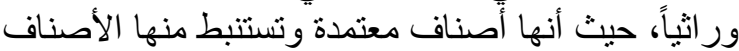

$$
\begin{aligned}
& \text { التوصيات } \\
& 1 \text { - تحديد المورثات المسؤولة عن تحمل الإجهاد الجفافي }
\end{aligned}
$$

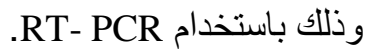

$$
\begin{aligned}
& 2 \text { - عزل البروتينات المسؤولة عن تحمل الصدمة. }
\end{aligned}
$$

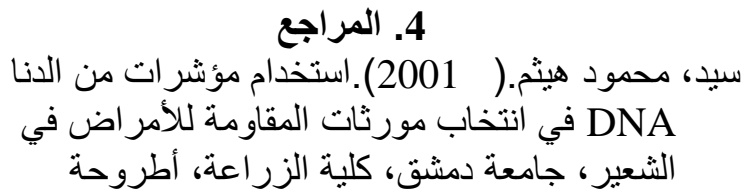

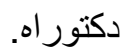

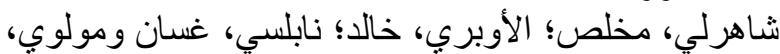

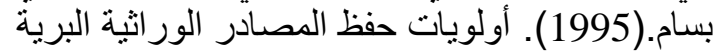

$$
\text { في سوريا، دمشق، سوريا. }
$$

\section{REFERENCES}

Ayad W.G., Hodgkin T., Jaradat A. and Rao V.R.(1997). Molecular genetic techniques for plant genetic resources. Report for an IPGRI workshop, IPGRI, Rome, Italy, P.p. 11-12.

Bornet B. and Branchard M.(2001). Non-anchored inter-simple sequence repeat (ISSR) markers: reproducible and specific tools for genome
نلاحظ من خلال الجدول (4) أن أقل قيمة لـ PDV هي

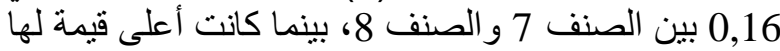

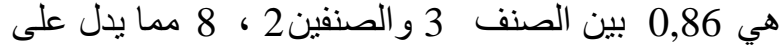
وجود تباين وراثي كبير بينها.

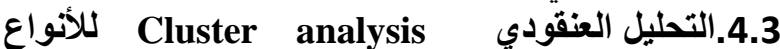
المدروسة والثاهد الناتج عن استخدام تقنية :ISSR

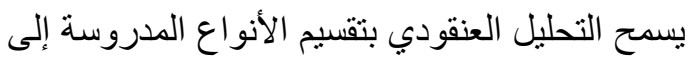

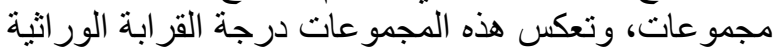

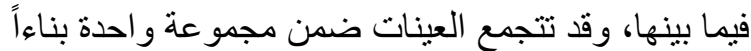
على موطنها الأصلي أو بناءاً على أصلى الصها ونسبها.

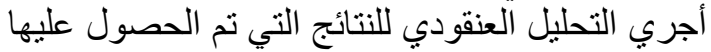

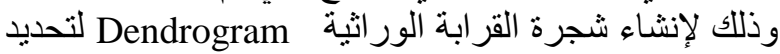

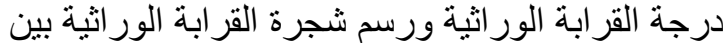

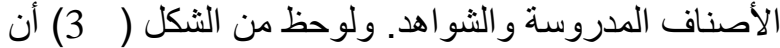

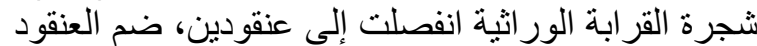

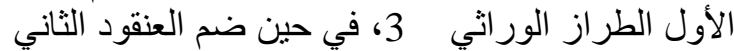

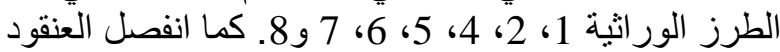

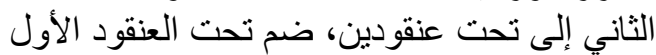

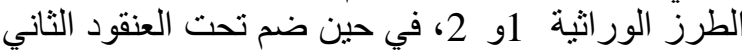
الطرز الور اثية 6، 5، 4 و والصنفان 7 و و8. كان الصنفان 7 و 8 الأقرب إلى بـ ور اثي (8,41)، ثم الطر ازين 5 و 6 ببعد ور الاثي(10,11)

fingerprinting. Plant Molecular Biology Reporter 22:427-432.

Bornet B. Goraguer F., Joly G. and Branchard M. (2002). Genetic diversity in European and Argentinean cultivated potatoes (Solanum tuberosum subsp. tuberosum) detected by intersimple sequence repeats (ISSRs). Genome 45: 481-484. 
Boyer J.S.(1982). Plant productivity and environment . Science 218,443-448 .

Chowdhury M.A., Vandenberg B. and Warkentin T. (2002). Cultivar identification and genetic relationship among selected breeding lines and cultivars in chickpea (Cicer arietinum L.). Euphytica 127:317-325.

Fernandez M.E., Figueiras A.M. and Benito C. (2002). The use of ISSR and RAPD markers for detecting DNA polymorphism, genotype identification and genetic diversity among barley cultivars with known origin. Theoretical and Applied Genetics 104: 845-851.

Graner A., Jahoor A., Schondelmaier J., Siedler H., Pillen K., Fischbeck G., Wenzel G., and Herrmann R.G. (1991). Construction of a RFLP map of barley. Theor Appl Genet 83:250-256.

Joshi S.P., Gupta V.S., Aggarwal R.K., Ranjekar P.K. and Brar D.S. (2000). Genetic diversity and phylogenetic relationship as revealed by intersimple sequence repeat (ISSR) polymorphism in the genus Oryza. Theoretical and Applied Genetics 100:1311-1320.

Karp A., Kresovich S., Bhat, Ayad W. G. and Hodgkin T. (1997). Molecular tools in plant genetic resources conservation: a guide to the technologies. 1st ed. IPGRI Technical Bulletin NO. 2. IPGRI, Rome, Italy, Pp. 9-21.

Lane A. (2007). An introduction to crop wild relatives, Geneflow, Publication about Agricultural Biodiversity, Bioversity International, p:19.

Maniatis T., Fritsch E.F. and Sambrook J. (1982). Molecular cloning: Laboratory manual. Cold Spring Harbor Laboratory Press, Cold Spring Harbor/ NY.

Mullis K. S. Faloona, Scharf S., Saiki R., Horn G., and Erlich H. (1986). Specific enzymatic amplification of DNA in vitro: The polymerase chain reaction. Cold Spring Harbor Symp. Quant. Biol. 51:263-273.

Nagaoka T. and Ogihara Y. (1997). Applicability of inter-simple sequence repeat polymorphisms in wheat for use as DNA markers in comparison to RFLP and RAPD markers. Theoretical and Applied Genetics 94: 597-602.
Powell W., Morgante M., Doyle J.J., Mcnical J., Tingey S.V. and Rafalski A.J. (1996). Genepool variation in genus Glycine subgenus Soja Revealed by polymorphic nuclear and chloroplast microsatellites, Genetics 144:793-803.

Qi, X., Stam P., and Lindhout P. (1996). Comparison and integration of four barley genetic maps. Genome 39:379-394.

Rafalski J.A., Vogel, Morgante M., Powell W., Andre C. and S.V. Tingey (1996). Generating and using DNA markers in plants. No mammalian Genomic Analysis: A Practical Guide. 4:75-134.

Ramsay L., Macaulay M., Degli Ivanissevich S., Maclean K., Carsle L., Fuller J., Edwards K.J., Tuvesson S., Morgante M., Massari A., Maestri E., Marmiroli N., Sjakste T., Ganal M., Powell W. and Waugh R. (2000). A simple sequence repeat- based linkage map of barley. Genetics 156:1997-2005.

Saiki R. K., Scharf S., Faloona F., Mullis K. B., Horn G. T., Eriich H. A. and Amheim N. (1985). Enzymatic amplification of b-globulin genomic sequences and restriction site analysis for diagnosis of sickle cell anaemia. Science 230:1350-1354.

Saiki R.K., Gelfand D.H., Stoffel S., Scharf S.J., Higuchi R., Horn G.T., Mullisand K.B. and Eriich H.A. (1988). Prime-directed enzymatic amplification of DNA with a thermostable DNA polymerase Science 239:487-491.

Tragoonrung S., Kanazin V., Hayes P.M. and Blake T.K. (1992). Sequence tagged site facilitated PCR for barley genome mapping. Theor. Appl. Genet. 84:1002-1008.

Williams J.G.K., Kubelik A.R., Livak K.J. Rafalski J.A and Tingey S.V. (1990). DNA polymorphisms amplified by arbitrary primers are useful as genetic markers. Nucleic Acids Research 18(22) 6531-6535.

Ziekiewicz E., Rafalski A. and Labuda A. (1994). Genome fingerprinting by simple sequence repeat (SSR) anchored polymerase chain reaction amplification. Genomics 20:178-183. 